\title{
Study of Aerosols Over Indian Subcontinent During El Niño and La Niña Events: Inferring Land-Air-Sea Interactions
}

\author{
PCS Devara ${ }^{1 *}$, K Vijayakumar², SM Sonbawne ${ }^{3}$, DM Giles ${ }^{4}$, BN Holben ${ }^{4}$, SVB Rao² and CK Jayasankar ${ }^{2}$ \\ ${ }^{1}$ Amity Centre for Ocean-Atmospheric Science and Technology (ACOAST) \& Amity Centre for Environmental Science \& Health (ACESH), Amity University
} Haryana, India

${ }^{2}$ Department of Physics, Sri Venkateswara University, India

${ }^{3}$ Indian Institute of Tropical Meteorology (IITM), India

${ }^{4}$ Nantional Aeronautics and Space Administration (NASA), USA

Submission: January 17, 2019; Published: January 29, 2019

*Corresponding author: PCS Devara, Centre for Ocean-Atmospheric Science and Technology \& Amity Centre for Environmental Science and Health, Amity University of Haryana, Manesar-Gurgaon, India

\begin{abstract}
In this paper, we have studied the role of aerosols in the interplay between land and sea during two weak and three strong episodic events, namely, La Niña [2005 (weak), 2008 (strong) and 2010 (strong)] and El Niño [2006 (weak) and 2009 (strong)]. For this purpose, the NCEP/ NCAR re-analysis data for the Niño 3.4 region and selected-domain, Arabian Sea (15o-20oN, 60o-71oE), based on HYSPLIT back-trajectory model analysis, in the proximity of experimental site data of sea surface temperature, and concurrent AERONET (land); MODIS and OMI (satellite) columnar data of aerosol optical depth, fine mode fraction and single scattering albedo have been analyzed. The main results reveal interesting features which include
\end{abstract}

a) Association between the selected-domain anomalies of sea surface temperature and land aerosol optical depth, single scattering albedo with good spatial resolution,

b) Positive relationship between sea surface temperature and fine mode fraction (land/sea) anomalies, implying the influence of anthropogenic aerosols, and

c) The impact of aerosols on La Niña and El Niño events over the land-air-ocean environment is found more pronounced at a lag of about two to three months, which is considered to be due to combined primary/secondary aerosol generation and advection processes. To substantiate the above findings, the results from the above data involving La Niña and El Niño episodes of weak / strong nature, combined with different aerosol types (carbonaceous, biomass burning, dust) and cloud parameters (cloud fraction, cloud optical depth and cloud top temperature), are also presented.

Keywords: Aerosols; Sun-sky radiometer; Aerosol optical depth; Single scattering albedo; Fine mode fraction; Cloud fraction; Cloud top temperature; La Niña and El Niño; Land-air-sea interaction

Abbreviations: ENSO: El Niño-Southern Oscillation; AOD: Aerosol Optical Depth; SSA: Single Scattering Albedo; FMF: Fine Mode Fraction; CF: Cloud Fraction; COD: Cloud Optical Depth; CTT: Cloud-Top Temperature; MODIS: Moderate Resolution Imaging Spectro-Radiometer; OMI: Ozone Monitoring Instrument; BC: Black Carbon; OC: Organic Carbon; ECMWF: European Centre for Medium-Range Weather Forecasts; MOC: Mostly Organic Carbon; NA: Non- Absorbing MA: Mixed Aerosol

\section{Introduction}

Aerosols such as dust, carbonaceous, biomass burning, smoke and volcanic are an integral part of the ocean-atmosphere system [1-4]. These constituents of both natural (dust, volcanoes etc.) and anthropogenic (biomass burning, fossil fuel etc.) origins play a pivotal role in the episodic events such as La Niña and El Niño through atmospheric cooling / warming, leading to floods / droughts over the Indian region [5]. El Niño-
Southern Oscillation (ENSO) is most basically an oscillation period of 2 to 7 years between cold La Niña and warm El Niño in the eastern and central Pacific Ocean water mass [6-7]. Warm phase - El Niño involves the anomalous warming of the ocean water mass and hence there is more convection of water vapour to the atmosphere above while the cold phase-La Niña involves the abnormal cooling of the ocean water that suppresses the convection above to the atmosphere [8]. Droughts are more 
pronounced over the Indian region during the El Niño (above $+0.5^{\circ} \mathrm{C}$ SST anomaly) and excess rainfall events are more pronounced during the La Niña (below - $0.50 \mathrm{C}$ SST anomaly). The threshold is further broken down into weak (with $0.5 \mathrm{oC}$ to $0.9^{\circ} \mathrm{C}$ SST anomaly), moderate $(1.0 \mathrm{oC}$ to $1.4 \mathrm{oC}$ SST anomaly) and strong $\left(1.5^{\circ} \mathrm{C}\right.$ SST anomaly). About the monsoon in Indian subcontinent, positive ENSO indices are more favourable to monsoon precipitation [9-10].

Studies of aerosol effects on air-sea coupled processes are sparse over the globe [11]. Aerosols have a significant impact upon the distribution and amount of rainfall modulating the entire hydrological cycle and this has major impact upon the monsoon water cycle that supports over $60 \%$ of the world's population. The Asian monsoon is especially very sensitive to the dust aerosol that is accumulated over the Tibetan highlands [1213]. Various researches have shown that the black carbon from the coal burning is the major cause of atmospheric circulation anomalies that finally resulted in long term drought over northern China and excessive rainfall over the southern China and India [14]. It is evident from the literature that atmospheric content of biomass burning aerosols and increases in dust aerosol export have been closely connected to the large-scale Material and Methodology phenomena occurring in the ocean-atmosphere system, like ENSO etc. [12-15]. There is evidence that these biomass burning aerosols have climatic effects since they change the radiative budget and regionally alter convective processes.

Prevailing SSTs during El Niño events play an important role by reducing the rate of aerosol removal from the atmosphere by rainfall [16]. Such effects are not limited to burning regions, but long-range transport of aerosols leads to a negative radiation anomaly over much of the Indian Ocean. Thus, SSTs may decrease over large areas [17]. Moreover, the characteristics of both continental and maritime aerosols drastically change due to two-way transport processes. Therefore, the observations of aerosol distributions over land in conjunction with those over the oceanic regions are essential and such observations will greatly help in understanding the nature and spatial extent of mixing of continental polluted air with pristine maritime air [18]. Therefore, the resultant aerosol of ocean-atmosphere environment will have mixed chemical composition and size distribution, which in turn will have different type of impact on SST and hence on El Niño and La Niña phenomena. Thus, the influence of aerosols in the ocean-atmosphere coupling is studied in this paper.

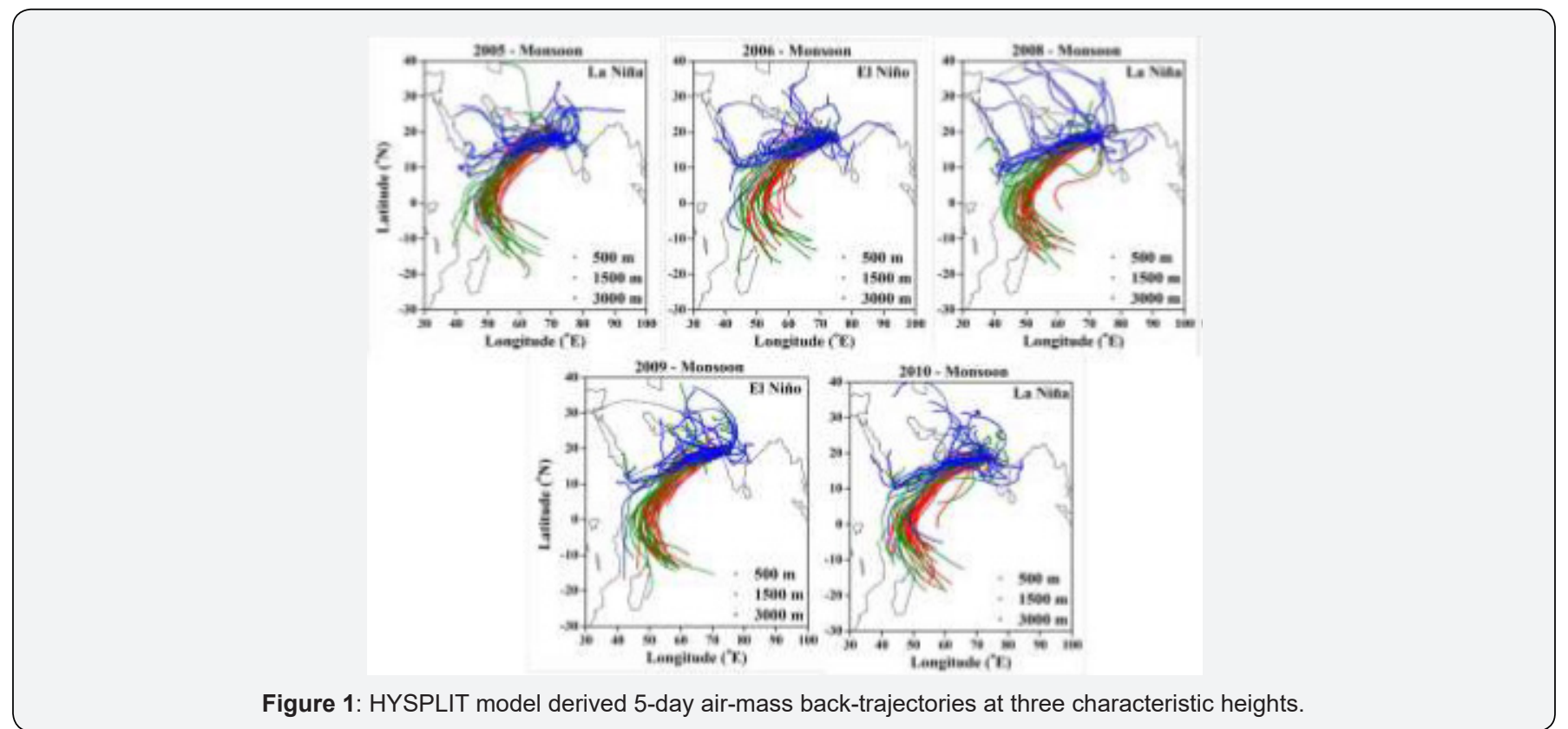

Here, we refer to, primarily, the boreal summer season (June, July, August, and September) and finally for all seasons together, in the present manuscript. While choosing the ENSO years, we have followed the standard method of 3-month (season) running mean in the NIN03.4 region. In order to classify a full-fledged El Niño or La Niña episode, these thresholds are considered to exceed the mean value for a period of at least 5 consecutive overlapping 3-month seasons.

In the present study, the NCEP/NCAR re-analysed SST data for the Niño 3.4 region $(5 \mathrm{oN}-5 \mathrm{oS}, 120 \mathrm{o}-170 \mathrm{oW})$ and over a selected- domain (15o-20oN, 60o-71oE) have been used. By following the HYbrid Single Particle Lagrangian Integrated Trajectory (HYSPLIT) multi-level (500, 1000 and $1500 \mathrm{~m})$ 5-day backtrajectory model analysis (Figure 1) for south-west monsoon period (from June through September) of 2005, 2006, 2008, 2009 and 2010 have been analyzed to examine the large-and small-scale connections between SST and aerosol parameters over land / sea regions. Basically, each trajectory represents the movement of air-mass. Depicted in the figure are the trajectories for the observation days in each season at different height levels during different calendar years. 
The above five years, considered in the present study, represent weak/strong phases of La Niña and El Niño. The concurrent aerosol (aerosol optical depth, AOD; single scattering albedo, SSA and fine mode fraction, FMF) and cloud (cloud fraction, CF; cloud optical depth, COD and cloud-top temperature, CTT) data from both Aeronet-Cimel Sun-sky radiometer (land) and Moderate resolution Imaging Spectro-radiometer (MODIS) and Ozone Monitoring Instrument (OMI) satellites (sea) have been analysed. AOD refers to columnar extinction or attenuation of solar radiation reaching the ground at any point of time at a specific wavelength of irradiance due to aerosol loading. SSA refers to columnar single scattering albedo (ratio between scattering and extinction) which is a gross indicator of absorption or scattering nature of aerosols, in turn, indicates atmospheric warming or cooling. FMF refers to columnar fine mode fraction, which is the fraction of fine-mode (particle radius less than 0.1 micron) in total aerosol ensemble. This quantity indicates a rough estimate of anthropogenic aerosols in an aerosol mixture [19]. The plots between anomalies of these parameters and those of SST are utilized to delineate the role of aerosols in air-sea interactions.

The categorization of aerosols and their percentage occurrence, prevailing over the study region, has been evaluated from the combined information about Ångström Exponent, AE (indicator of aerosol size distribution), AOD, FMF and SSA. In this analysis, we followed mainly the method suggested by Lee et al. [20]. In this method, the FMF and SSA have been used to infer the dominant aerosol size mode, and to distinguish absorbing from non-absorbing aerosols, respectively. Thus, the aerosol types are classified based on dominant size mode and radiation absorptivity determined by the FMF and SSA, respectively. The FMF criterion is like that for Black Carbon (BC), Organic Carbon $(O C)$ (i.e. $F M F>0.6$ ) whereas these species are separated with different SSA values. For BC, SSA should be $\leq 0.9$ while for ${ }^{\circ} \mathrm{C}$, SSA should be $0.95>$ SSA $>0.9$.

The synoptic maps of wind, temperature and humidity fields, obtained from the European Centre for Medium-Range Weather Forecasts (ECMWF) re-analysis data at $850 \mathrm{hPa}$ pressure level, were used to explain the circulation-driven long-range transport and growth processes of aerosols during the study period. It is clear from Figure 1 that, albeit there are some sporadic contributions of air-mass from the regions around gulf countries, including deserts, the maximum contribution to the study region comes from the marine aerosols of Arabian Sea and Indian Ocean. This region is termed as 'selected domain (15o-20oN, $60 \mathrm{o}-71 \mathrm{oE}$ )' in the present study.

The experimental station (Pune, India) is in the Deccan Plateau in Maharashtra State and is about $100 \mathrm{~km}$ away from the West coast. The prevailing environment over the experimental station is urban and the aerosol type present over the observation site is largely a mixture of water-soluble, dust and soot-like aerosols. Very hot weather associated with maximum dust load and cumulonimbus-type cloud development during late afternoon to evening prevails over the station during the pre-monsoon season (March-May). The airflow in the lower troposphere is predominantly westerly during the summer monsoon season (June-September), which brings in a large influx of moist air from the Arabian Sea. The wind in the lower troposphere reverses with the withdrawal of the monsoon and the easterly flow sets in during post-monsoon season (OctoberNovember). The air-mass, rich in nuclei of continental origin, passes over the region during this season. Also, an increase of dry polar continental air in the wake of low-pressure systems (western disturbances) takes place during the winter season (December-February). Thus, the synoptic meteorological conditions at the experimental station vary markedly from continental (winter) to maritime (summer) environment. More details can be found in Devara et al. [21-22].

The influence of mean meteorological fields over India and its neighborhood on aerosol parameters provide useful information on cloud microphysical and dynamical properties and associated precipitation characteristics during the monsoon season. To investigate such aspects, composite maps of the ECMWF re-analysis daily data of wind, air temperature and specific humidity at $850 \mathrm{hPa}$ pressure-level over India have been examined. It is found that winds are stronger over the source locations in Arabian Peninsula during El Niño years compared to La Niña years. The west to east temperature gradients may influence the pressure gradient during El Niño year. This implies strong eastward wind flow towards the Indian region during El Niño year. These intense east-west winds are capable of transporting aerosols in large quantities towards the study region. However, during La Niña years winds are generally weaker and confined to smaller area and contribute to lesser quantity of aerosol transported eastward towards the study region. A wet and cool condition that occurs during La Niña years (2005, 2008 and 2010) decreases the production and propagation of mineral dust aerosols. These results corroborate those reported in the literature by Abish \& Mohanakumar [4].

\section{Discussion of Results}

The association between aerosol / cloud parameters and SST for the Niño 3.4 region was found to be like that for the selected domain; hence the former relationship is not discussed here. Moreover, the shifts observed between the parameters may also be due to time synchronization between the measurements.

\section{Influence of aerosol types}

To characterize aerosols in terms of optical, physicochemical and radiative properties, the patterns of AOD, AE, SSA and FMF have been utilized to discriminate aerosol types such as clean continental (PC), mostly black carbon (MBC), mostly organic carbon (MOC), non- absorbing (NA) and mixed aerosol (MA) (Kaufman et al. 1995). The occurrence of these aerosols over the experimental region, Pune (18 32 N, 7351 E, 559m above mean sea level) during the study period is shown plotted 
as a stacked diagram in Figure 2. The percentage occurrence of different types of aerosols during the selected La Niña and El Niño years is presented in Table 1. It is evident that UI/BB aerosols are less dominant during the weak phase of El Niño (2006); more dominant during strong phase of El Niño (2009) and strong phase of La Niña $(2008,2010)$ while these aerosols dominate during weak phase of La Niña (2005) after MBC. This implies that besides UI, MBC from biomass burning or forest fires seem to dominate during 2006 and 2010 while BC aerosols during 2005. In addition, MOC from biomass burning can be noted only during 2010 which is strong phase of La Niña.

Table 1: Aerosol types observed during different phases of El Niño and La Niña events.

\begin{tabular}{|c|c|c|c|c|c|}
\hline $\begin{array}{c}\text { Aerosol } \\
\text { Type }\end{array}$ & $\begin{array}{c}\mathbf{2 0 0 5} \\
\text { La Niña } \\
\text { (Weak) }\end{array}$ & $\begin{array}{c}\mathbf{2 0 0 6} \\
\text { El Niño } \\
\text { (Weak) }\end{array}$ & $\begin{array}{c}\mathbf{2 0 0 8} \\
\text { La Niña } \\
\text { (Strong) }\end{array}$ & $\begin{array}{c}\mathbf{2 0 0 9} \\
\text { El Niño } \\
\text { (Strong) }\end{array}$ & $\begin{array}{c}\mathbf{2 0 1 0} \\
\text { La Niña } \\
\text { (Strong) }\end{array}$ \\
\hline CM & 0.71 & 0.29 & 2.61 & 0 & 1.25 \\
\hline DD & 13.51 & 13.62 & 13.86 & 18.02 & 14 \\
\hline UI/BB & 30.57 & 41.45 & 32.6 & 35.9 & 35 \\
\hline PC & 9.48 & 5.51 & 14.56 & 8 & 13.75 \\
\hline MBC & 33.65 & 29.57 & 20.72 & 21.59 & 18 \\
\hline MOC & 0.47 & 0.29 & 0.34 & 0.18 & 6.5 \\
\hline NA & 0 & 0 & 2 & 0 & 1 \\
\hline MA & 11.61 & 9.28 & 13.32 & 17.29 & 10.5 \\
\hline
\end{tabular}

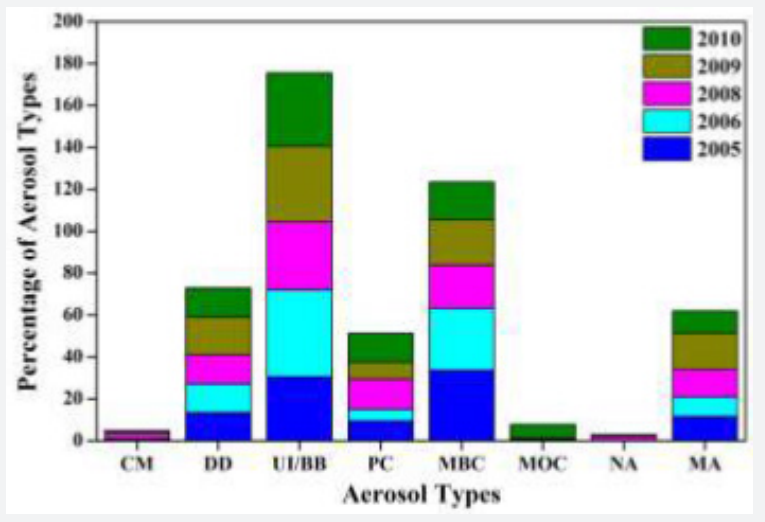

Figure 2: Percentage of different types of aerosol over Pune during 2005, 2006, 2008, 2009 and 2010.

\section{Association between land and sea parameters}

The anomalies of AOD from Aeronet Sun-sky radiometer data and the concurrent selected domain SST data from NCEP/ NCAR re-analysis are plotted in Figure 3. It is evident from the figure that both parameters show an opposite relationship during monsoon period (characterized by cloud- and rain-out phenomena), implying warmer SSTs are associated with lower AODs, indicating dominant local absorbing aerosols compared to marine scattering-type in all the five years considered in the study. Interestingly, during post-monsoon months, both AOD and SST follow each other for the El Niño years, could be mainly due to dry soil besides long-range transport of dust particles.

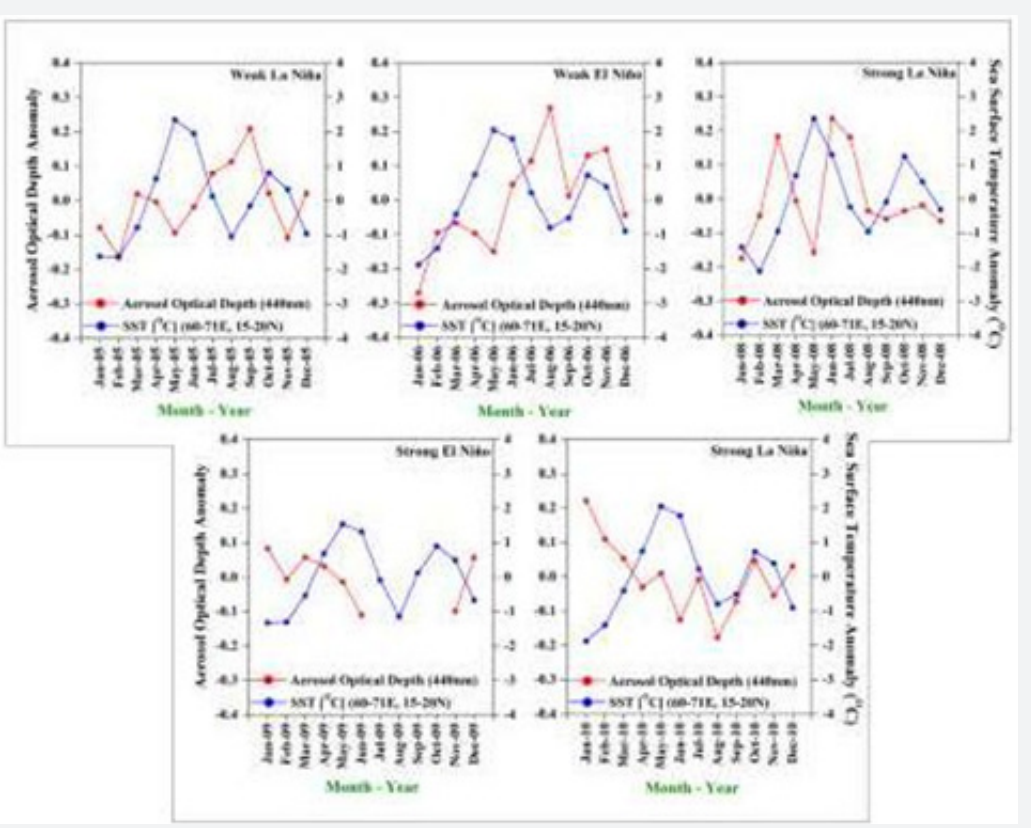

Figure 3: HYSPLIT model derived 5-day air-mass back-trajectories at three characteristic heights.

\section{Association within marine parameters}

Figure 4 depicts the affinity between anomalies of AOD from OMI and SST over the selected domain. The magnitude of anomalies in the present case, where both measurements over sea, is found to be larger as compared to the variations observed between land and sea. Albeit the variations in both parameters show an opposite nature, as opposed to the feature observed in Figure 3, greater AOD anomalies are associated with lower SST anomalies, indicating dominance of sea salt particles which are basically scattering type aerosols. 


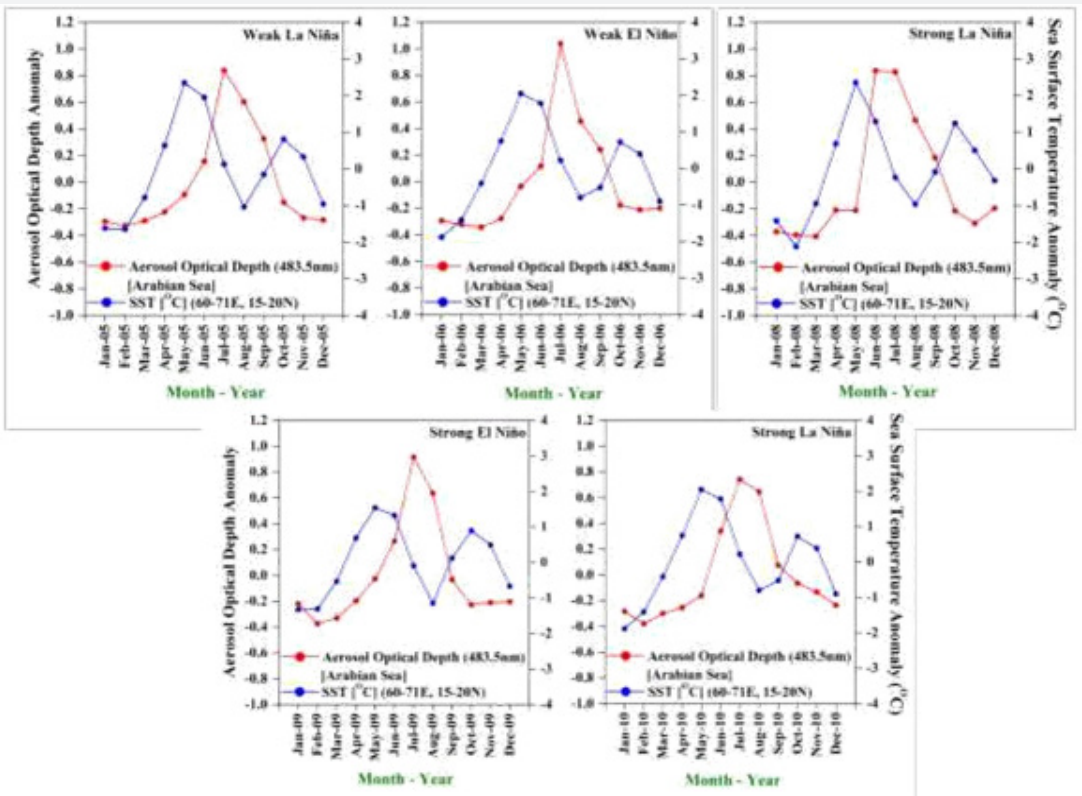

Figure 4: Association between marine AOD and SST during the EI Niño and La Niña years.

\section{Correspondence between SST and FMF}

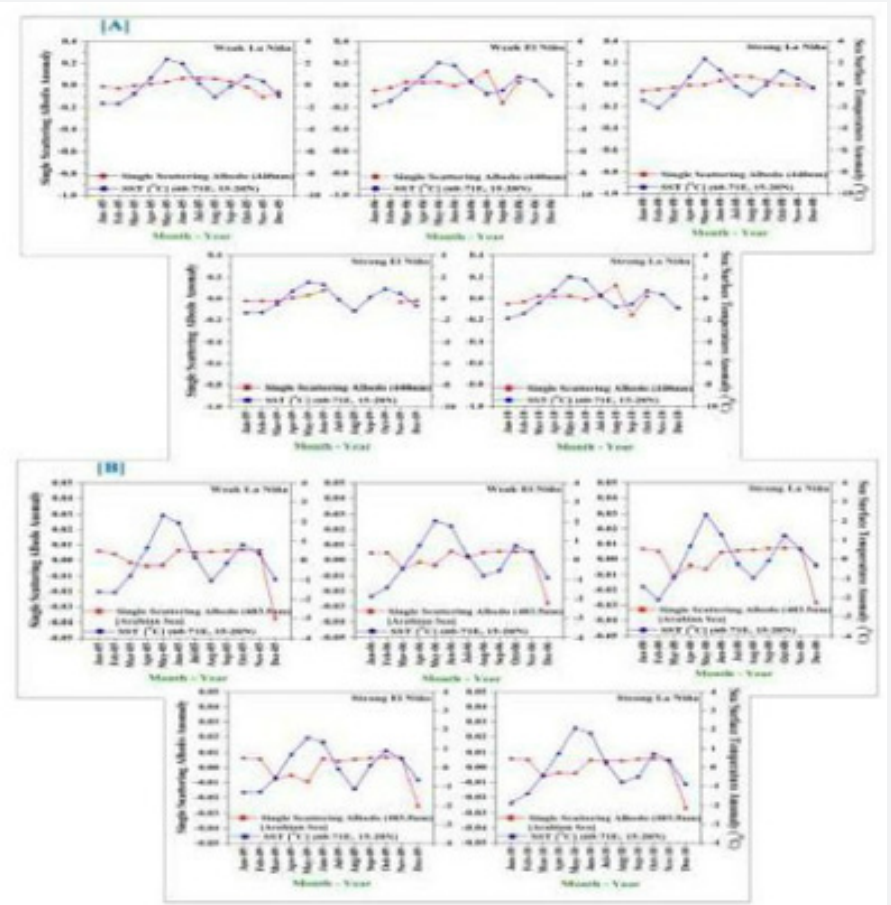

Figure 5: Relationship between SST and FMF over land $[A]$ and over ocean $[B]$.

The fine mode fraction of aerosols is a good indicator of anthropogenic activity. The coherence between the anomalies of SST with land and marine FMF are displayed in Figure 5 (A and $\mathrm{B}$ ), respectively. The anomalies are stronger over sea as compared to those over land-sea comparison as explained in the previous section. Both parameters exhibit lower values and good correspondence during monsoon months for the study period, which is consistent due to precipitation / cloud scavenging processes. In the case of land-sea comparison, the correspondence is seen even during the post-monsoon months also as in the case of AOD.

\section{Affinity between SSA and SST}

SSA is the ratio of scattering to extinction of the radiation due to aerosols, characterizes the combined effect of their scattering and absorption properties due to particles. The variations in 
the anomaly of SST against those of SSA over land (A) and over sea (B) for the considered period are shown plotted in Figure 6 ( $A$ and $B$ ). The anomalies of SSA over land are larger (almost an order of magnitude) compared to those over sea, implying greater concentration of absorbing aerosols over land. The anomalies of both parameters follow each other in the case of sea aerosols whereas the relationship between SSA and SST is very weak (sometimes opposite trend) over land as compared to that over the sea. This is clearly seen in the figure wherein the correlation coefficient and associated probabilities (statistical significance) are indicated.

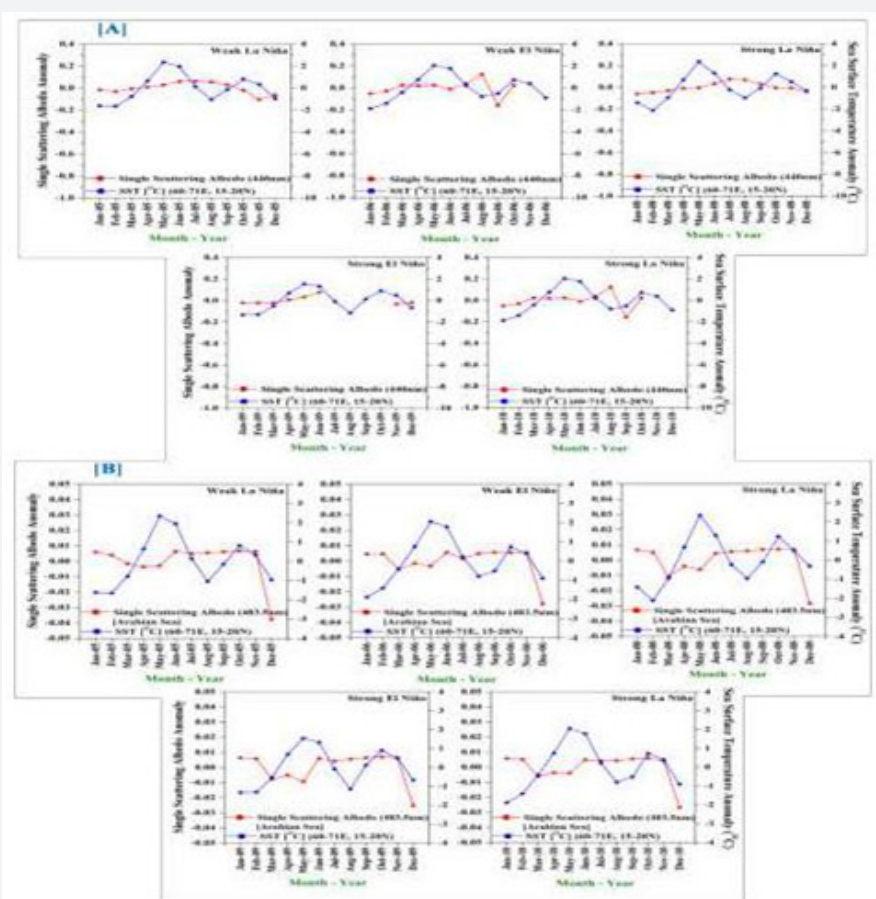

Figure 6: Association between SST and SSA-land [A] and SSA-ocean [B] during 2005, 2006, 2008, 2009 and 2010.
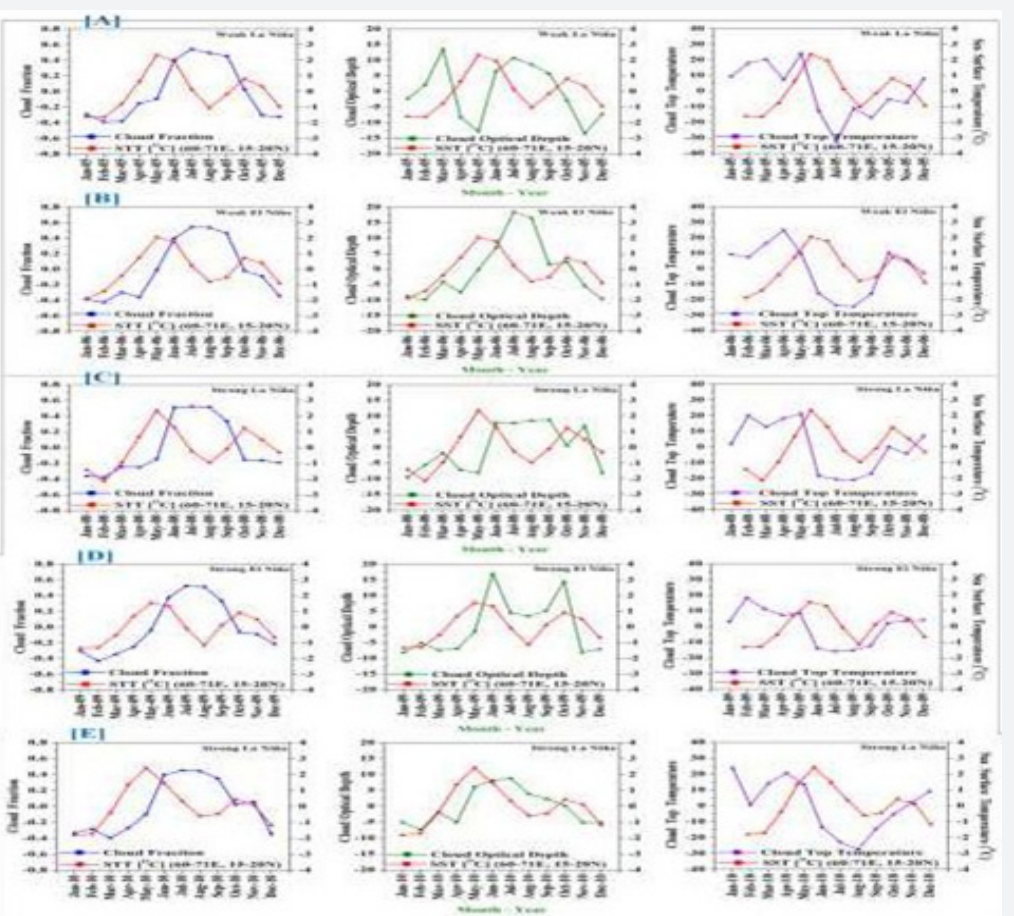

Figure 7: Correspondence between Single Scattering Albedo (SSA), Sea Surface Temperature (SST), and Cloud Fraction (CF), Cloud Optical Depth (COD) and Cloud Top Temperature (CTT) during 2005 [A], 2006 [B], 2008 [D] and 2010 [E]. 
ssociation between cloud parameters and SST During 2005, 2006 and 2010

Figure 7 (A, B, C) portrays association between anomalies of SST with CF, COD and CTT. In all the three years under consideration, enhancement in cloud fraction or cloud cover is found to associate with decrease in SST during monsoon period. This could be due to higher cloud fraction inhibits the incoming

\section{Affinity between aerosol-ocean-atmosphere parameters}

Table 2: Correlation between different parameters of air and ocean during El Niño and La Niña periods.

\begin{tabular}{|c|c|c|c|c|c|c|c|}
\hline \multirow{2}{*}{ S.No. } & \multirow{2}{*}{ Year } & \multicolumn{2}{|c|}{ Zero Lag } & \multicolumn{2}{|c|}{ Two Months Lag } & \multicolumn{2}{|c|}{ Three Months Lag } \\
\hline & & Correlation (R) & P Value & Correlation (R) & P Value & Correlation (R) & P Value \\
\hline \multirow[t]{6}{*}{1.} & \multicolumn{7}{|c|}{ AOD $440 \mathrm{~nm}$ Vs. SST (Arabian Sea) } \\
\hline & 2005 & -0.04 & 0.9 & 0.4 & 0.26 & 0.88 & 0.002 \\
\hline & 2006 & 0.18 & 0.57 & 0.56 & 0.09 & 0.68 & 0.04 \\
\hline & 2008 & 0.04 & 0.9 & 0.26 & 0.48 & 0.09 & 0.82 \\
\hline & 2009 & -0.63 & 0.09 & -0.45 & 0.37 & 0.22 & 0.72 \\
\hline & 2010 & -0.47 & 0.13 & -0.53 & 0.11 & -0.47 & 0.2 \\
\hline \multirow[t]{6}{*}{2.} & \multicolumn{7}{|c|}{ AOD 483.5nm (Arabian Sea) Vs. SST (Arabian Sea) } \\
\hline & 2005 & 0.12 & 0.71 & 0.81 & 0.004 & 0.7 & 0.04 \\
\hline & 2006 & 0.14 & 0.66 & 0.85 & 0.002 & 0.64 & 0.07 \\
\hline & 2008 & 0.18 & 0.58 & 0.72 & 0.02 & 0.46 & 0.22 \\
\hline & 2009 & 0.03 & 0.92 & 0.79 & 0.01 & 0.55 & 0.12 \\
\hline & 2010 & 0.2 & 0.54 & 0.87 & 0.001 & 0.69 & 0.04 \\
\hline \multirow[t]{6}{*}{3.} & \multicolumn{7}{|c|}{ FMF 500 nm Vs. SST (Arabian Sea) } \\
\hline & 2005 & -0.04 & 0.2 & -0.72 & 0.02 & -0.42 & 0.27 \\
\hline & 2006 & -0.31 & 0.32 & 0.75 & 0.01 & -0.56 & 0.12 \\
\hline & 2008 & -0.25 & 0.44 & 0.44 & 0.2 & -0.24 & 0.54 \\
\hline & 2009 & -0.96 & 0.0001 & 0.11 & 0.84 & 0.35 & 0.56 \\
\hline & 2010 & 0.47 & 0.12 & -0.55 & 0.1 & -0.33 & 0.39 \\
\hline \multirow[t]{6}{*}{4.} & \multicolumn{7}{|c|}{ FMF 500 nm (Arabian Sea) Vs. SST (Arabian Sea) } \\
\hline & 2005 & -0.35 & 0.26 & -0.56 & 0.1 & -0.34 & 0.37 \\
\hline & 2006 & -0.38 & 0.22 & -0.57 & 0.08 & -0.39 & 0.31 \\
\hline & 2008 & -0.17 & 0.6 & -0.32 & 0.37 & 0.25 & 0.51 \\
\hline & 2009 & -0.33 & 0.3 & -0.38 & 0.28 & -0.26 & 0.5 \\
\hline & 2010 & -0.46 & 0.13 & -0.54 & 0.11 & -0.33 & 0.38 \\
\hline \multirow[t]{6}{*}{5.} & \multicolumn{7}{|c|}{ SSA 440 nm Vs. SST (Arabian Sea) } \\
\hline & 2005 & 0.32 & 0.31 & 0.36 & 0.3 & 0.35 & 0.35 \\
\hline & 2006 & 0.22 & 0.55 & 0.2 & 0.61 & -0.09 & 0.85 \\
\hline & 2008 & 0.27 & 0.4 & 0.62 & 0.05 & 0.63 & 0.07 \\
\hline & 2009 & 0.75 & 0.03 & 0.21 & 0.69 & -0.04 & 0.95 \\
\hline & 2010 & 0.22 & 0.55 & 0.2 & 0.64 & -0.09 & 0.85 \\
\hline \multirow[t]{6}{*}{6.} & \multicolumn{7}{|c|}{ SSA 483.5 nm (Arabian Sea) Vs. SST (Arabian Sea) } \\
\hline & 2005 & 0.15 & 0.65 & 0.001 & 1 & 0.2 & 0.6 \\
\hline & 2006 & 0.11 & 0.74 & 0.03 & 0.93 & 0.32 & 0.4 \\
\hline & 2008 & -0.05 & 0.87 & 0.06 & 0.87 & 0.27 & 0.48 \\
\hline & 2009 & -0.01 & 0.96 & 0.09 & 0.8 & 0.25 & 0.51 \\
\hline & 2010 & 0.06 & 0.86 & 0.12 & 0.74 & 0.39 & 0.3 \\
\hline
\end{tabular}




\section{International Journal of Environmental Sciences \& Natural Resources}

\begin{tabular}{|c|c|c|c|c|c|c|c|}
\hline 7. & \multicolumn{7}{|c|}{ CF Vs. SST (Arabian Sea) } \\
\hline & 2005 & 0.3 & 0.34 & 0.69 & 0.03 & 0.69 & 0.04 \\
\hline & 2006 & 0.31 & 0.33 & 0.77 & 0.01 & 0.79 & 0.01 \\
\hline & 2008 & 0.16 & 0.61 & 0.71 & 0.02 & 0.65 & 0.06 \\
\hline & 2009 & 0.23 & 0.48 & 0.74 & 0.01 & 0.71 & 0.03 \\
\hline & 2010 & 0.28 & 0.38 & 0.81 & 0.004 & 0.77 & 0.02 \\
\hline \multirow[t]{6}{*}{8.} & \multicolumn{7}{|c|}{ COD Vs. SST (Arabian Sea) } \\
\hline & 2005 & -0.31 & 0.32 & 0.38 & 0.28 & 0.75 & 0.02 \\
\hline & 2006 & 0.29 & 0.36 & 0.75 & 0.01 & 0.67 & 0.05 \\
\hline & 2008 & 0.09 & 0.79 & 0.51 & 0.13 & 0.62 & 0.08 \\
\hline & 2009 & 0.48 & 0.15 & 0.2 & 0.57 & 0.32 & 0.4 \\
\hline & 2010 & 0.58 & 0.05 & 0.7 & 0.02 & 0.38 & 0.32 \\
\hline \multirow[t]{6}{*}{9.} & \multicolumn{7}{|c|}{ CTT Vs. SST (Arabian Sea) } \\
\hline & 2005 & -0.12 & 0.72 & -0.72 & 0.02 & -0.61 & 0.08 \\
\hline & 2006 & 0.05 & 0.88 & -0.93 & 0.0001 & -0.81 & 0.01 \\
\hline & 2008 & 0.01 & 0.97 & -0.73 & 0.02 & -0.75 & 0.02 \\
\hline & 2009 & -0.13 & 0.7 & -0.76 & 0.01 & -0.76 & 0.02 \\
\hline & 2010 & -0.02 & 0.95 & -0.85 & 0.002 & -0.92 & 0.0004 \\
\hline
\end{tabular}

In order to investigate, further, the roles of aerosols between land and sea during El Niño and La Niña events, a correlation (at different lags of 0, 2 and 3 months between the parameters) analysis has been carried out to the data sets. A summary of this analysis is presented in a dedicated table (Table 2), indicating $\mathrm{R}$ (correlation) and $\mathrm{P}$ (significance) values. The results reveal a significant association at accepted level (in a regression analysis designed to show statistical significance) between land and sea parameters during different phases of El Niño and La Niña at lag of 2 and 3 months, with a relatively better association at lag of 2 months, as compared to the direct (zero lag) relationship, during their strong phase, in particular, which corroborate the aerosol types observed during different phases of El Niño and La Niña. From the table 2, such an association can be clearly seen between FMF and SST, SSA and SST, CF and SST and CTT and SST. These aspects clearly show a significant relationship between aerosols over land and ocean air mass and their combined role in the El Niño and La Niña phenomena, which could be attributed to the primary/secondary aerosol generation and advection processes. The low correlations observed in the study may be explained mainly due to data sample size and partly due to phase of the episode. Detailed studies are planned in our future work.

\section{Conclusion}

The impact of aerosols on ocean-atmosphere coupled system during different phases of episodic events such as El Niño and La Niña has been investigated utilizing Niño 3.4 SST, AERONET (land), MODIS, OMI (space-borne) aerosol data sets. The results reveal both positive and negative association between the anomalies of SST and aerosol / cloud parameters depending on the phase / refractive index of aerosols prevailing and circulation features over the experimental region. An opposite relationship was found between the anomalies of Niño 3.4 SST and land AOD, SSA with a phase shift which could be due to time synchronization and/or spatial difference between the measurements. This aspect has been further investigated by undertaking the lag correlation analysis between the parameters considered for the study, both for the entire study period and for the boreal summer period. The correlation coefficient is found to be improved in both the cases. This implies that SST, SSA and FMF have better association with AOD, indicating that the landair-sea phenomena are related at a lag of about 2 to 3 months in the case of total study period (January-December) and almost one-to-one relationship in the case of boreal summer (JuneSeptember) period. This is supported by detailed statistical analysis of data for the study period. The results are explained based on multi-level air-mass 5-day back trajectory model analysis and synoptic meteorological elements to infer the long-range transport and growth processes of aerosols. All the trajectories during monsoon months of all five years considered in the study indicate the arrival of air-mass from sea region. The results also show that the UI/BB aerosols are less dominant during the weak phase of El Niño (2006); more dominant during strong phase of El Niño (2009) and strong phase of La Niña $(2008,2010)$ while these aerosols dominate during weak phase of La Niña (2005) after MBC. This implies that besides UI, MBC from biomass burning or forest fires seem to dominate during 2006 and 2010 while MBC aerosols from burning of fossil fuel during 2005. In addition, MOC from biomass burning can be noted only during 2010 which is strong phase of La Niña. The cooler SSTs are found to support generation/production of more cloud-active aerosols, which is a signature of aerosol indirect effect. The results are promising to enhance understanding of feedbacks on ENSO physics by ocean-atmosphere system. 


\section{Acknowledgements}

This work was supported jointly by the ISRO-GBP-ICARB/ ARFI; IITM, Pune; and Amity University Haryana (AUH), Panchgaon-Manesar-Gurgaon. The authors thank the NCEP/ NCAR (http://www.cpc.ncep.noaa.gov/data/indices/sstoi. indices) and ECMWF for the re-analysis data Niño 3.4 and meteorological fields. The MODIS and OMI satellite data and AERONET Sun-sky radiometer ground-based data used in this work is gratefully acknowledged. The authors are also thankful to the authorities of AUH, Panchgaon, Haryana; and SVU, Tirupati, Andhra Pradesh, India for their constant encouragement, motivation and infrastructure support. KV is indebted to ISRO, Bangalore for financial support. Thanks, are due to all the collaborating Institutions and their Ministries in India and abroad for their support

\section{References}

1. Stenchikov G, Delworth TL, Ramaswamy V, Stouffer RJ, Wittenberg A, et al. (2009) Volcanic signals in oceans. J Geophys Res 114(D16).

2. Canon J, Valdes J (2011) Assessing the influence of global climate and anthropogenic activities on water balance of an Andean Lake. J Water Res Protect 3: 883-891.

3. Chrastansky A, Rotstayn LD (2012) The effect of ENSO-induced rainfall and circulation changes on the direct and indirect radiative forcing from Indonesian biomass-burning aerosols. Atmos Chem Phys 12 11395-11416.

4. Abish B, Mohanakumar K (2013) Absorbing aerosol variability over the Indian subcontinent and its increasing dependence on ENSO. Global and Planet Change 106: 13-19.

5. Bates BC, Kundzewicz ZW, Wu S, Polutikof JP (2008) Climate Change and Water. Technical Paper of the Intergovernmental Panel on Climate Change. In: Bates BC, Kundzewicz ZW, Wu S, Polutikof JP (Eds.), IPCC Secretariat, Geneva, pp. 210.

6. Philander GS (1990) El Niño, La Niña and the Southern Oscillation, Academic Press, New York, NY, USA.

7. Wu ZJ, Colman R, Power S, Wang X, McAvaney B (2002) The El Niño Southern Oscillation response in the BMRC Coupled GCM. BMRC Research Report No. 91, pp. 29.

8. Xue Y, Shukla J (1997) Model simulation of the influence of global SST anomalies on the Sahel rainfall. COLA Preprint 41, Centre for Ocean, Land, Atmosphere Studies, Calverton, Maryland.

9. Gadgil S, Rajeevan M, Francis PA (2007) Monsoon variability: Links to major oscillations over the equatorial Pacific and Indian oceans, Special Section: Indian Monsoon. Cur Sci 93: 182-194.

10. Gadgil S (2008) The Indian monsoon. Part 4. Links to Cloud Systems over the Tropical Oceans, Resonance 13(3): 218-235.

11. Cropp RA, Gabric AJ, Gabric GH, Mctainsh, Brick GH, et al. (2005) Coupling between ocean biota and atmospheric aerosols: Dust, dimethyl- sulphide, or artifact? Global Biogeochemical Cycles 19(4): 1-13.

12. Jacobson MZ (2001) Strong radiative heating due to the mixing state of black carbon in atmospheric aerosols. Nature 409: 695-697.

13. Ramanathan V, Crutzen PJ, Kiehl JT, Rosenfeld D (2001) Climate effects of black carbon aerosols in China and India. Science 294: 2119-2124.

14. Menon S, Hansen J, Nazarenko l, Luo Y (2002) Climate effects of black carbon aerosols in China and India. Science 297(5590): 2250-2252.

15. Gong SL, Zhang XY, Zhao TL, Zhang XB, Barrie LA, et al. (2006) Simulated climatology of Asian dust aerosol and its trans-Pacific transport. Part II: Interannual variability and climate connections. J Clim 19: 104122.

16. Van der Werf GR, Randerson JT, Giglio L, Collatz GJ, Mu M, et al. (2010) Global fire emissions and the contribution of defore-station, savanna, forest, agricultural, and peat fires (1997-2009). Atmos Chem Phys 10: 11707-11735.

17. Lamarque JF, Bond TC, Eyring V, Granier C, Heil A, et al. (2010) Historical (1850-2000) gridded anthropogenic and biomass burning emissions of reactive gases and aerosols: methodology and application. Atmos Chem Phys 10: 4963-5019.

18. Devara PCS, Maheskumar RS, Raj PE, Dani KK, Sonbawne, SM (2001) Some features of columnar aerosol optical depth, ozone and precipitable water content observed over land during the INDOEX-IFP 99. Meteorol Zeitschrift 10(2): 123-130.

19. Devara PCS, Sumit Kumar, Pandithurai G, Safai PD, Dipu S (2013) Comparison between urban aerosol products retrieved from collocated Cimel and Prede Sun/sky radiometers at Pune, India. Meteorol Atmos Phys 120(3-4): 189-200.

20. Lee J, Kim J, Song CH, Chun Y, Sohn BJ, et al. (2010) Characteristics of aerosol types from AERONET sunphotometer measurements. Atmos Environ 44(26): 3110-3117.

21. Devara PCS, Raj PE, Sharma S, Pandithurai G (1994) Lidar-observed long-term variations in urban aerosol characteristics and their connection with meteorological parameters. Int J Climatol 14(5): 581-591.

22. Devara PCS, Maheskumar RS, Raj PE, Pandithurai G, Dani KK (2002) Recent trends in aerosol climatology and air pollution as inferred from multi-year lidar observations over a tropical urban station. Int I Climatol 22(4): 435-449.

23. Kaufman YJ, Koren I, Remer LA, Rosenfeld D, Rudich Y (2005) The effect of smoke, dust, and pollution aerosols on shallow cloud development over the Atlantic Ocean. Proc Nat Acad Sci 102(32): 11207-11212.

24. Quaas J, Ming Y, Menon S, Takemura T, Wang M, et al. (2009) Aerosol indirect effects and general circulation model inter-comparison and evaluation with satellite data. Atmos Chem Phys 9: 8697-8717.

25. Sekiguchi M, Nakajima T, Suzuki K, Kawamoto K, Higurashi A, et al. (2009) A study of the direct and indirect effects of aerosols using global satellite data sets of aerosol and cloud parameters. J Geophys Res 108 (D22): 4699.

26. Myhre G, Stordall F, Johnsrud M, Kaufman YJ, Rosenfeld D, et al. (2007) Aerosol-cloud interaction inferred from MODIS satellite data and global aerosol models. Atmos Chem Phys 7: 3081-3101. 

will reach you the below assets

- Quality Editorial service

- Swift Peer Review

- Reprints availability

- E-prints Service

- Manuscript Podcast for convenient understanding

- Global attainment for your research

- Manuscript accessibility in different formats ( Pdf, E-pub, Full Text, Audio)

- Unceasing customer service

Track the below URL for one-step submission https://juniperpublishers.com/online-submission.php 